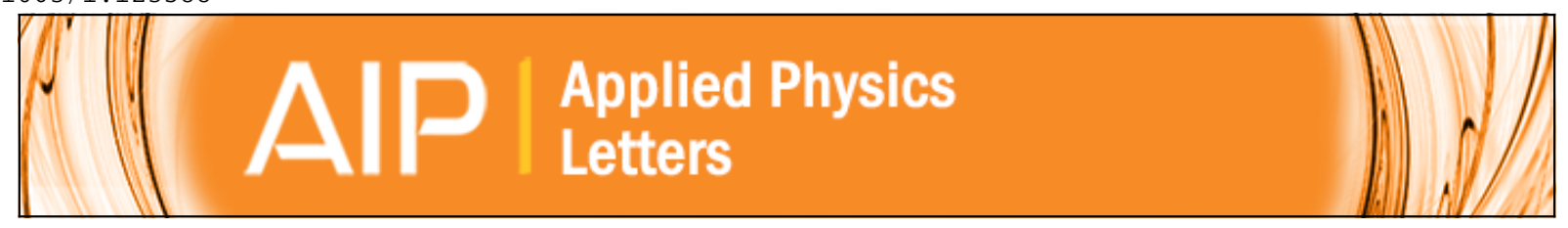

Highly c-axis oriented $\mathrm{Pb}(\mathrm{Zr}, \mathrm{Ti}) \mathrm{O} 3$ thin films grown on Ir electrode barrier and their electrical properties

K. B. Lee, S. Tirumala, and S. B. Desu

Citation: Applied Physics Letters 74, 1484 (1999); doi: 10.1063/1.123588

View online: $h$ ttp://dx.doi.org/10.1063/1.123588

View Table of Contents: http://scitation.aip.org/content/aip/journal/apl/74/10?ver=pdfcov

Published by the AIP Publishing 


\title{
Highly $\mathrm{c}$-axis oriented $\mathrm{Pb}(\mathrm{Zr}, \mathrm{Ti}) \mathrm{O}_{3}$ thin films grown on Ir electrode barrier and their electrical properties
}

\author{
K. B. Lee, ${ }^{\text {a) }}$ S. Tirumala, and S. B. Desu \\ Department of Materials Science and Engineering, Thin Film Laboratory, Virginia Tech., \\ Blacksburg, Virginia 24061-0237
}

(Received 2 November 1998; accepted for publication 11 January 1999)

\begin{abstract}
We have investigated the structural and electrical properties of sol-gel derived $\mathrm{Pb}(\mathrm{Zr}, \mathrm{Ti}) \mathrm{O}_{3}(\mathrm{PZT})$ thin films deposited on Ir electrode barrier ( $\mathrm{Ir} / \mathrm{poly}-\mathrm{Si} / \mathrm{SiO}_{2} / \mathrm{Si}$ ). Owing to the interface-controlled growth, highly $c$-axis oriented perovskite PZT thin films were obtained for the postdeposition annealing temperature of $580^{\circ} \mathrm{C}$. Additionally, we found that the ferroelectric properties of $\mathrm{IrO}_{2} / \mathrm{PZT} / \mathrm{Ir} /$ poly-Si capacitors were remarkably changed by the partial pressure of oxygen during the deposition of $\mathrm{IrO}_{2}$ top electrodes, which could be due to the enhanced reaction of $\mathrm{IrO}_{2}$ with PZT by the oxygen ion bombardments. Remanent polarization and coercive field of $\mathrm{IrO}_{2} / \mathrm{PZT} / \mathrm{Ir} /$ poly-Si capacitor with the top electrodes deposited at $P_{\mathrm{O}_{2}}=1 \mathrm{mTorr}$ was $20 \mu \mathrm{C} / \mathrm{cm}^{2}$ and $30 \mathrm{kV} / \mathrm{cm}$, respectively, and showed negligible polarization fatigue up to $10^{11}$ switching repetitions. The leakage current density at a field of $80 \mathrm{kV}$ was $5 \times 10^{-8} \mathrm{~A} / \mathrm{cm}^{2}$. (C) 1999 American Institute of Physics. [S0003-6951(99)01510-7]
\end{abstract}

The development of high-density nonvolatile ferroelectric memories (NvFRAMs) is one of the interesting subjects in fields of memory devices. In a one transistor-one capacitor (1T-1C) NvFRAM cell structure, ${ }^{1}$ the bottom electrode of the capacitor is directly contacted with poly-Si plug, which in turn is connected to the source/drain of the transistor in the memory cell. Hence, the bottom electrode is required to act as an oxygen diffusion barrier in order to prevent the reaction of oxygen with poly-Si plug at highly oxidizing ambient during the fabrication of ferroelectric film. In addition, $\mathrm{Pb}(\mathrm{Zr}, \mathrm{Ti}) \mathrm{O}_{3}$ (PZT) based high-density NvFRAMs require the bottom electrode of the capacitor to help in eliminating the degradation properties, such as polarization fatigue, aging, and retention. Recently, Ir and $\mathrm{IrO}_{2}$ have attracted attention as electrode materials for PZT thin film capacitors since they showed high quality ferroelectric properties which are comparable to those of Pt/PZT/Pt capacitors. However, most reported PZT capacitors with such electrodes have hybrid electrode structures ${ }^{2-4}$ such as $\mathrm{Pt} / \mathrm{IrO}_{2}$ and $\mathrm{Ir} / \mathrm{IrO}_{2}$. Since they have more complex processes and relatively large thickness, such electrode structures may be unsuitable for the integration of NvFRAMs. Moreover, if one would try to use such hybrid electrodes as a bottom electrode in the 1T-1C cell structure, the additional layer ${ }^{5}$ for oxygen barrier should be needed in order to protect the reaction of oxygen with poly-Si. Hence, the development of a simple and thin electrode-barrier structure is necessary from the practical aspect point of view. Recently, we have successfully prepared the high-quality PZT capacitor having the most simple structure, $\mathrm{IrO}_{2} / \mathrm{PZT} / \mathrm{Ir} /$ poly-Si, which showed that $\mathrm{Ir}$ in itself could act as an electrode barrier. In this letter, we present the microstructures and electrical properties of PZT thin films deposited onto Ir/poly-Si substrates. An attempt is made to realize the origin of orientation of PZT thin films during the

\footnotetext{
${ }^{a)}$ Permanent address: Department of Physics, Sangji University, Wonju, Kangwondo 220-702, Korea. Electronic mail: kblee@vt.edu
}

growth. As a result, we could successfully prepare highly $c$-axis oriented perovskite rich PZT thin films. In order to characterize the electrical properties of PZT thin film capacitor, we also investigated the effect of top electrodes on their electrical properties.

Ir layer of $120 \mathrm{~nm}$ thickness was deposited onto $n^{+}$ poly- $\mathrm{Si} / \mathrm{SiO}_{2} / \mathrm{Si}$ wafers using a radio-frequency (rf) magnetron sputtering process, which is described elsewhere. ${ }^{5} \mathrm{PZT}$ thin films of about $250 \mathrm{~nm}$ thickness, with a composition of $\mathrm{Pb}_{1.1}\left(\mathrm{Zr}_{0.53} \mathrm{Ti}_{0.47}\right) \mathrm{O}_{3}$, were deposited on Ir/poly-Si by means of a conventional sol-gel method, which is described elsewhere. ${ }^{6}$

Figure 1 shows the x-ray diffraction (XRD) patterns of $\mathrm{PZT} / \mathrm{Ir} /$ poly-Si thin films annealed at different temperatures. It could be seen that all PZT thin films annealed at temperatures greater than $560{ }^{\circ} \mathrm{C}$ had perovskite single phase with

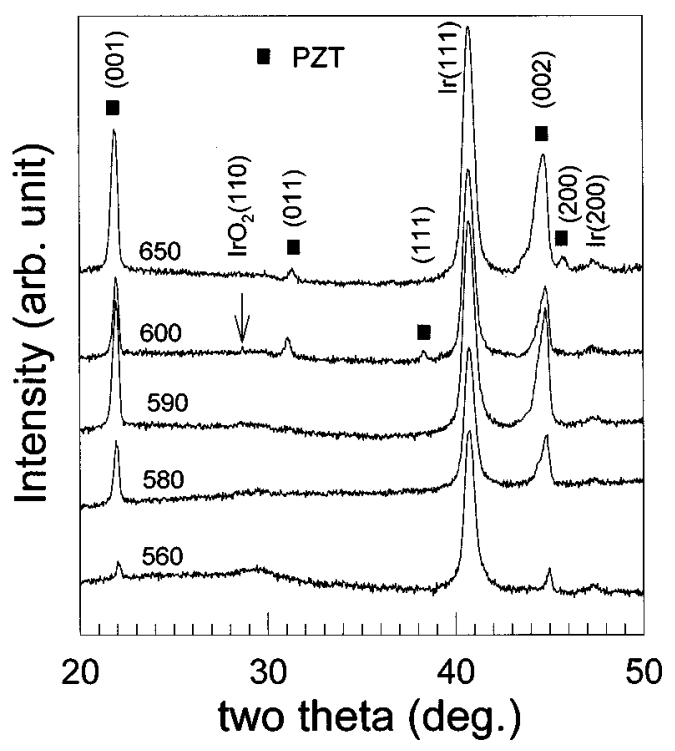

FIG. 1. X-ray diffraction patterns of PZT/Ir/poly-Si thin films postannealed at different temperatures ranging from 560 to $650{ }^{\circ} \mathrm{C}$. 
highly $c$-axis orientation. However, for annealing temperatures greater than $600^{\circ} \mathrm{C}$, PZT (011) and (111) peaks appeared in XRD patterns of Fig. 1, which were accompanied with small $\mathrm{IrO}_{2}(110)$ peak at $2 \theta=28.4^{\circ}$. Such $\mathrm{IrO}_{2}$ peaks could be accompanied by the formation of an amorphous $\mathrm{Pb}-\mathrm{Ir}-\mathrm{O}$ phase formed due to the reaction of $\mathrm{Ir}$ with $\mathrm{PbO}$ in PZT during annealing process. Work done earlier by our group $^{7}$ had shown that PZT thin films processed on asdeposited $\mathrm{IrO}_{2} / \mathrm{Ir}$ electrodes possessed random orientation. Additionally, it was also shown that PZT thin films processed on annealed $\mathrm{IrO}_{2} / \mathrm{Ir}$ electrodes a possessed a greater tendency of $c$-axis orientation. While our sol-gel derived PZT thin films deposited on a $\mathrm{Pt} / \mathrm{Ti} / \mathrm{SiO}_{2} / \mathrm{Si}$ substrate exhibited highly (111) preferred orientation, ${ }^{6}$ those deposited on Ir/poly-Si substrates showed highly $c$-axis orientation. The fact that the orientation of PZT thin films is related to the materials of bottom electrodes implies that the crystallization of PZT thin films on metal electrodes is mainly dominated by the interface-controlled growth. The orientation of PZT thin films on Pt bottom electrode, as reported by many workers, depends strongly on the heating treatments as well as on the deposition methods. Among them, Chen and $\mathrm{Chen}^{8}$ suggested the interface growth in PZT, that is, when a (111)oriented $\mathrm{Pt}_{5-7} \mathrm{~Pb}$ intermetallic phase was formed during the pyrolysis step, it provided the template for the growth of (111)-oriented PZT, while if (001) PbO formed first a (001) PZT orientation was observed since there is a reasonable lattice match between (001) $\mathrm{PbO}$ and (001) PZT. In the case of $\mathrm{PZT} / \mathrm{Ir} /$ poly-Si, amorphous $\mathrm{Pb}-\mathrm{Ir}-\mathrm{O}$ phase was the most possible interfacial phase between PZT and Ir bottom electrodes. ${ }^{9}$ Hence, we assumed that highly $c$-axis oriented PZT on Ir might be due to the preferential growth so as to minimize surface energy, since a (001) texture represented minimum surface energy. On the other hand, if once (111) or (110) $\mathrm{IrO}_{2}$ phases were formed, growth of PZT might be interfered by solid-phase epitaxial effect resulting in randomly oriented PZT films. However, further investigations would be needed in order to confirm our assumption.

We investigated the fundamental electrical properties, such as $P-E$ hysteresis loop, polarization fatigue behavior, and the leakage current-voltage $(I-V)$ characteristics, of highly $c$-axis oriented PZT thin film capacitors annealed at $580^{\circ} \mathrm{C}$. The details of the electrical measurement are described elsewhere. ${ }^{5,7}$ All the electrical measurements were performed by using a two probe contact between the surface of poly-Si and $\mathrm{IrO}_{x}$ top electrode. The $\mathrm{IrO}_{x}$ top electrodes of $3.5 \times 10^{-4} \mathrm{~cm}^{2}$ area and $80 \mathrm{~nm}$ thickness were deposited using the rf-reactive sputtering of $\mathrm{Ir}$ target in $\mathrm{Ar}+\mathrm{O}_{2}$ ambience. The partial pressure of $\operatorname{Ar}\left(P_{\mathrm{Ar}}\right)$ was fixed at 2 mTorr, but that of $\mathrm{O}_{2}\left(P_{\mathrm{O}_{2}}\right)$ was varied from zero to 3 mTorr in order to investigate the optimum deposition conditions of $\mathrm{IrO}_{x}$ top electrode. Figure 2 shows the typical $P-E$ hysteresis loops of $\mathrm{IrO}_{x} / \mathrm{PZT} / \mathrm{Ir} /$ poly-Si capacitors with different $P_{\mathrm{O}_{2}}$. It can be seen that as $P_{\mathrm{O}_{2}}$ is increased, the symmetry of the $P-E$ hysteresis loop has increased, which is also shown in the inset of Fig. 2 as a plot of median between two coercive field $\left(+E_{c}\right.$ and $\left.-E_{c}\right)$ vs $P_{\mathrm{O}_{2}}$. In order to interpret these results, we investigated the compositional ratio of $\mathrm{Ir} / \mathrm{O}$ in $\mathrm{IrO}_{x}$ with different $P_{\mathrm{O}_{2}}$ using electron spectroscopy for chemical analy-

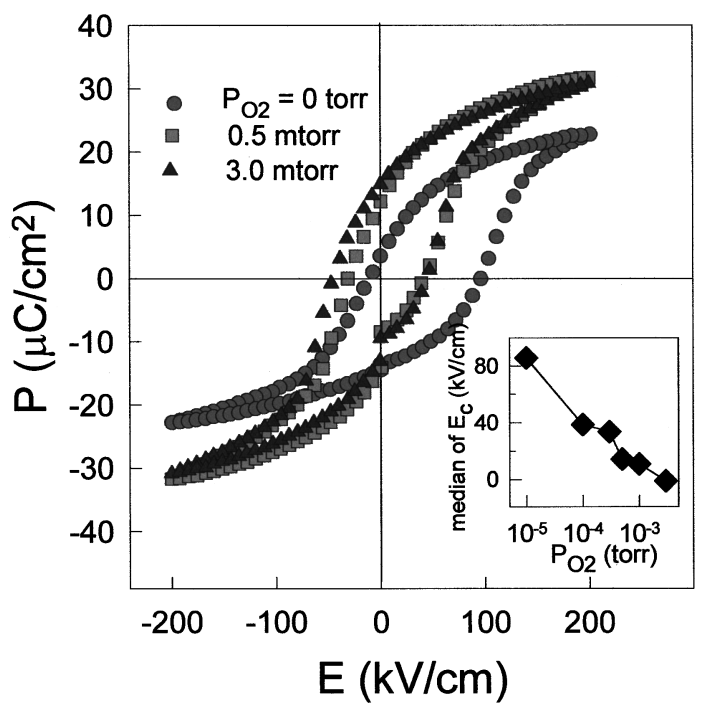

FIG. 2. Typical $P-E$ hysteresis loops of $\mathrm{IrO}_{2} / \mathrm{PZT} / \mathrm{Ir} /$ poly-Si capacitors, where $\mathrm{IrO}_{2}$ top electrode were sputter deposited at different oxygen partial pressures, $P_{\mathrm{O}_{2}}$. The inset of this figure shows the plot of median of $E_{c}\left[=\left(+E_{c}\right)+\left(-E_{c}\right)\right]$ vs $P_{\mathrm{O}_{2}}$.

sis (ESCA). However, for all $\mathrm{IrO}_{x}$ films deposited with different $P_{\mathrm{O}_{2}}$, the atomic ratios of $\mathrm{Ir} / \mathrm{O}$ were absolutely the same as $32 / 68$, which corresponded to $\mathrm{IrO}_{2}$. Hence, we thought that the results in Fig. 2 might be due to the oxygen ion bombardments during the deposition of top electrodes rather than due to the oxygen contents in $\mathrm{IrO}_{2}$ top electrodes. As $P_{\mathrm{O}_{2}}$ was increased, the oxygen ion bombardments with the PZT/Ir/poly-Si substrates were increased, which enhanced the reaction of top $\mathrm{IrO}_{2}$ with PZT. The interfacial states between top $\mathrm{IrO}_{2}$ electrodes and PZT need to be the same as those between PZT and bottom Ir electrodes in order to obtain a symmetrical $P-E$ hysteresis loop. $P_{r}$ was about $20 \mu \mathrm{C} / \mathrm{cm}^{2}$ at applied voltages of $5 \mathrm{~V}(200 \mathrm{kV} / \mathrm{cm})$ and $E_{c}$ was about $40 \mathrm{kV} / \mathrm{cm}$ for PZT capacitors with the top electrode deposited at $P_{\mathrm{O}_{2}}$ greater than 0.5 mTorr. Figure 3 shows the typical polarization-fatigue behaviors of PZT capacitors with different top electrodes. In Fig. 3, the normalized difference between the switched and nonswitched polar-

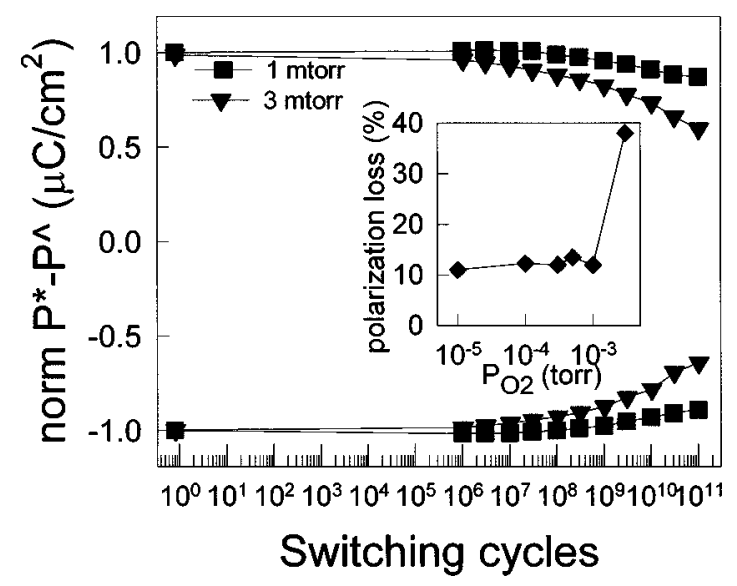

FIG. 3. Typical polarization fatigue behaviors of $\mathrm{IrO}_{2} / \mathrm{PZT} / \mathrm{Ir} /$ poly-Si capacitors having different $\mathrm{IrO}_{2}$ top electrode deposited at $P_{\mathrm{O}_{2}}$. The inset of these figure shows the plot of polarization loss after $1 \times 10^{11^{2}}$ switching repetitions vs $P_{\mathrm{O}_{2}}$ 


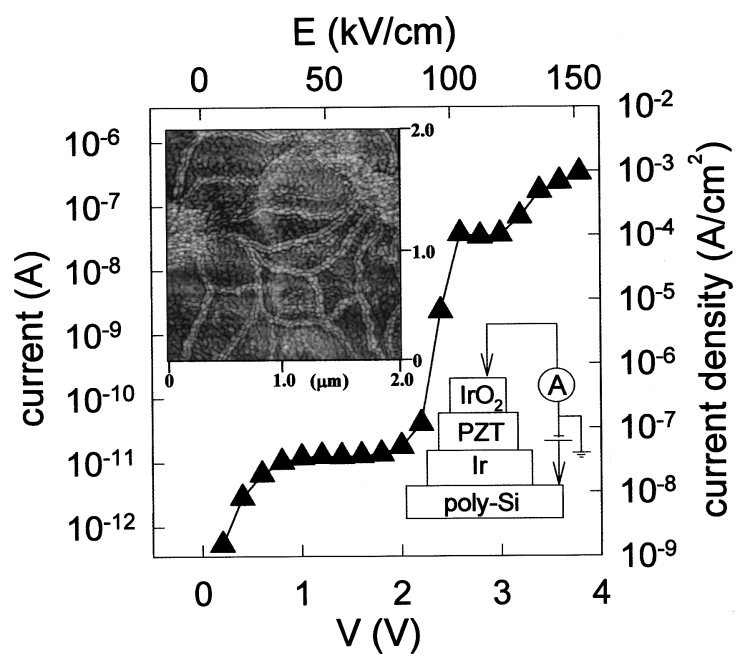

FIG. 4. Leakage current-voltage characteristic of $\mathrm{IrO}_{2} / \mathrm{PZT} / \mathrm{Ir} /$ poly-Si capacitor having $\mathrm{IrO}_{2}$ top electrode deposited at $P_{\mathrm{O}_{2}}=1 \mathrm{mTorr}$. The inset of this figure shows an atomic force microscopy image $\left(2 \times 2 \mu \mathrm{m}^{2}\right)$ of the surface of PZT/Ir/poly-Si capacitor.

ization $\left(P^{*}-P^{\wedge}\right)$ was plotted as a function of switching cycles applied to the capacitors. It could be observed in the inset of Fig. 3 that all capacitors with $\mathrm{IrO}_{2}$ top electrodes deposited at $P_{\mathrm{O}_{2}}$ less than 1 mTorr had negligible fatigue loss of around $10 \%$ after $1 \times 10^{11}$ polarization repetitions. However, PZT capacitor $\mathrm{IrO}_{2}$ top electrodes deposited at $P_{\mathrm{O}_{2}}=3$ mTorr exhibited about $40 \%$ polarization loss. Such results indicated that excessive reaction of the top electrode with PZT by oxygen ion bombardments could be a cause of defects which might be the origin of polarization fatigue in PZT capacitors. Hence, a well controlled top electrode deposition might enhance the fatigue resistivity of PZT capacitors. Figure 4 shows the $I-V$ characteristics of $\mathrm{IrO}_{2} / \mathrm{PZT} / \mathrm{Ir} /$ poly-Si capacitors with the top electrodes deposited at $P_{\mathrm{O}_{2}}=1 \mathrm{mTorr}$. In Fig. 4 , it could be seen that for fields smaller than $80 \mathrm{kV} / \mathrm{cm}$, the leakage current densities were below $1 \times 10^{-7} \mathrm{~A} / \mathrm{cm}^{2}$. However, above intermediate fields of $80 \mathrm{kV} / \mathrm{cm}$, a high leakage current of around 1 $\times 10^{-4} \mathrm{~A} / \mathrm{cm}^{2}$ could be seen, which was normally observed for PZT capacitors with high defect concentration, such as for PZT capacitors with conducting oxide electrodes. This suggests that in the $\mathrm{IrO}_{2} / \mathrm{PZT} / \mathrm{Ir} /$ poly-Si capacitors, the undetected interfacial phase formed at the interface between
PZT film and both electrodes might have diminished the microstructure of PZT layer. Hence, there could have been enough defect states in PZT layer which caused the PZT capacitors to be leaky. Such a fact could be confirmed from atomic force microscopic images $\left(2 \times 2 \mu \mathrm{m}^{2}\right)$ of the PZT/Ir/ poly-Si surface, as shown in the inset of Fig. 4, which showed an appreciable amount of second phase nonuniformly distributed on the surface of PZT layer.

Conclusively, we have prepared highly $c$-axis oriented PZT thin films deposited on Ir/poly-Si. The orientation of these films were believed to be controlled by the preferential growth on the interfacial phase of amorphous $\mathrm{Pb}-\mathrm{Ir}-\mathrm{O}$ so as to minimize surface energy. The ferroelectric properties of $\mathrm{IrO}_{2} / \mathrm{PZT} / \mathrm{Ir} /$ poly-Si capacitor were remarkably changed by the partial pressure of oxygen during the deposition of $\mathrm{IrO}_{2}$ top electrodes, which was due to the enhanced reaction of $\mathrm{IrO}_{2}$ with PZT by the oxygen ion bombardments. PZT capacitors with $\mathrm{IrO}_{2}$ top electrodes deposited at $P_{\mathrm{O}_{2}}$ $=1 \mathrm{mTorr}$ exhibited a highly symmetric $P-E$ hysteresis loop with remanent polarization and coercive field of 20 $\mu \mathrm{C} / \mathrm{cm}^{2}$ and $30 \mathrm{kV} / \mathrm{cm}$, respectively, and showed lack of polarization fatigue up to $10^{11}$ switching repetitions. The leakage current densities at a field of 80 and $120 \mathrm{kV}$ were $5 \times 10^{-4}$ and $1 \times 10^{-4} \mathrm{~A} / \mathrm{cm}^{2}$, respectively. The results of this work proved that Ir in itself could act as an bottom electrode barrier for PZT capacitor. If one could reduce the interfacial phases between PZT and electrodes, the leakage current behaviors would further improve and high quality $\mathrm{IrO}_{2} / \mathrm{PZT} / \mathrm{Ir} /$ poly-Si capacitors with a simple electrodebarrier structure could be fabricated for high density NvFRAMs.

${ }^{1}$ R. Rameshi, W. K. Chan, B. Wiikens, H. Gilchrist, T. Sands, J. M. Tarascon, V. G. Keramdas, D. K. Fork, J. Lee, and A. Safari, Appl. Phys. Lett. 61, 1537 (1992).

${ }^{2}$ T. Nakamura, Y. Nakao, A. Kamisawa, and H. Takasu, Appl. Phys. Lett. 65, 1522 (1994).

${ }^{3}$ T. Nakamura, Y. Nakao, A. Kamisawa, and H. Takasu, Jpn. J. Appl. Phys., Part 1 34, 5184 (1995).

${ }^{4}$ M. Shimizu, H. Okino, H. Fujisawa, and T. Shiosaki, ISAF Proc. IEEE Int. Symp. Appl. Ferroelectrics 10, 471 (1996).

${ }^{5}$ K. B. Lee, Y. Song, S. Tirumala, and S. B. Desu (unpublished).

${ }^{6}$ Y. Song, Y. Zhu, and S. B. Desu, Appl. Phys. Lett. 72, 2686 (1998).

${ }^{7}$ K. B. Lee, S. Tirumala, and S. B. Desu (unpublished).

${ }^{8}$ S. Y. Chen and I. W. Chen, J. Am. Ceram. Soc. 77, 2332 (1994).

${ }^{9}$ M. Shimizu, H. Fujisawa, S. Hyodo, S. Nakashima, H. Niu, H. Okino, and T. Shiosaki, Ferroelectric Thin Films IV (Material Research Society, Boston, 1997), Vol. 493, p. 159. 